\title{
La búsqueda de una identidad artística La abstracción en las ideas de Luis Miró Quesada'
}

\author{
Christopher Schreier Barreto \\ Universidad de Lima, Perú
}

Recibido: 14 de octubre de 2015 / Aprobado: 3 de diciembre de 2015

En arquitectura, la abstracción fue empleada por la modernidad para distanciarse de los estilos arquitectónicos, como una búsqueda de simplicidad volumétrica y negación del pasado.Luis Miró Quesada desarrolló los conceptos de formas y fórmulas, para diferenciar la composición arquitectónica como una búsqueda por sintetizar las formas básicas, a diferencia de aquella que se basaba en preceptos compositivos relacionados con los estilos locales. En dicha dualidad, Luis Miró Quesada define la diferencia entre ornamento y decoración, con el objetivo de enfatizar los aspectos técnicos y constructivos del edificio, como característica compositiva de la arquitectura moderna.

abstracción, arquitectura, modernidad, estilos

\section{The Search for an Artistic Identity. Abstraction in the Ideas of Luis Miró Quesada}

In Architecture, abstraction was used by modernity to take distance from architectural styles, while looking for volumetric simplicity and denial of past. Luis Miró Quesada developed the concepts of forms and formulas to distinguish architectural composition, as a means of synthesizing the basic forms, different from the other one based on rules of composition related to local styles. In this context of duality, Luis Miró Quesada defines the difference between ornament and decoration; his intention is to emphasize the technical and constructional aspects of buildings, as a composition feature in Modern Architecture.

abstraction, architecture, modernity, styles

1 El presente artículo ha sido elaborado en un inicio, como parte del curso Arquitectura Moderna, dictado por el arquitecto Elio Martuccelli en la maestría de Arquitectura, con mención en Historia, Teoría y Crítica, de la Universidad Nacional de Ingeniería, durante el año 2015. 
En la modernidad, el arte y la arquitectura tuvieron que encontrar nuevas formas de expresar las inquietudes de una época contradictoria, que reclamaba un cambio social y cultural, exigiendo a los artistas la búsqueda de una expresión auténtica de la época, capaz de representar los avances tecnológicos y la independencia artística en todas las áreas de producción cultural. Esta búsqueda significaba además un subyacente rechazo de las formas y significados que el arte desarrollaba hasta entonces.

Uno de los mecanismos que utilizó la modernidad para la exploración de este nuevo arte fue la abstracción. Concebida por contradicción, la abstracción aparece como una necesidad de diferenciarse con respecto al arte figurativo, generando la relación dialéctica abstracción-figuración. Así podemos identificar en el arte abstracto una negación del arte figurativo, una negación de las formas de producción artística premodernas y, por consecuencia, una negación del pasado.

En el contexto de las vanguardias artísticas del siglo XX, la abstracción desarrolló dos maneras de ser interpretada. La primera está relacionada con la negación de transmitir un mensaje de manera explícita.En este sentido, el arte abstracto se libera de la responsabilidad y el peso que el mensaje transfiere, permitiendo la exploración sin límites y las múltiples interpretaciones que el espectador quiera otorgarle. La segunda tiene que ver con la composición a través de la sintetización del objeto artístico en formas básicas. De esta manera, la abstracción fomenta la exploración geométrica mediante formas y volúmenes, sin un mensaje evidente.

Durante las décadas de 1940 y 1950 aparecieron en el Perú dos grupos de artistas e intelectuales que defendían las ideas de la modernidad y proponían dejar atrás el arte figurativo: la Generación del 51 y la Agrupación Espacio (Castrillón, 2002). Aunque ambas agrupaciones trabajaban sobre la misma base, fue la Agrupación Espacio la que comunicó sus ideas con mayor intensidad y logró un mayor impacto mediático, debido al liderazgo de Luis Miró Quesada y la posibilidad de publicar semanalmente en el diario El Comercio. En 1947 publican en dicho diario su manifiesto Expresión de principios de la "Agrupación Espacio" (Miró Quesada, 1947), en donde hacen público su reclamo de un cambio en la producción de arte y arquitectura en el Perú, con el objetivo de alcanzar una producción internacional. Aunque la formación y publicación del manifiesto de la Agrupación Espacio es considerada como un suceso importante de coalición para la defensa de la arquitectura moderna y las ideas sobre la abstracción, para Luis Miró Quesada la publicación de su libro de 1945 Espacio en el tiempo. La arquitectura moderna como fenómeno cultural, es un antecedente aún más relevante, que expresa sus intereses teóricos y su compromiso con el proyecto moderno. Durante esos años se desarrolló un debate entre Sebastián Salazar Bondy y Luis Miró Quesada, a través de algunos artículos en El Comercio (Miró Quesada) y La Prensa (Salazar Bondy), en los cuales se expuso el enfrentamiento entre el arte abstracto y el arte figurativo, por la búsqueda de una identidad nacional en el arte.

Es importante precisar que la modernidad, como cualquier otro movimiento cultural, no comienza de improviso sino que se superpone $\mathrm{y}$ tiene que coexistir con movimientos previos, de los que busca diferenciarse y de los que 
inevitablemente recibe influencia. Para el caso peruano, esto significó que la modernidad debía coexistir en sus inicios con la arquitectura neocolonial (de carácter neobarroco), la indigenista y la neoperuana (Martuccelli, 2000, p. 65). En dicha transición, la arquitectura moderna buscó su autorreferencialidad en la desvinculación histórica, dejando al margen reivindicaciones precolombinas o hispánicas, proponiendo a su vez un arte abstracto. Para Luis Miró Quesada esta desvinculación cultural se materializa en la arquitectura, en el momento en que el arquitecto comienza a componer el edificio a través del uso de formas geométricas, dejando de pensar en los elementos decorativos que lo recubren y lo cargan de significado.

Pero, ¿es posible pensar que la modernidad en el Perú buscaba cortar la continuidad en la producción artística de ascendencia colonial o precolombina, para así conservarla y evitar su transgresión? ¿Es posible pensar que la modernidad a través de la abstracción pudo aportar a la construcción de una nueva identidad en el arte y la arquitectura peruanos al igual que el arte figurativo?

\section{LO ABSTRACTO SEgÚN LUIS MIRÓ QUESADA}

En el año 1945 Luis Miró Quesada, personaje fundamental en el pensamiento de la arquitectura moderna, publica su texto Espacio en el tiempo. La arquitectura moderna como fenómeno cultural. Esta publicación es un manifiesto sobre la modernidad, escrita desde dentro de la modernidad peruana, pero sin pretender construir nuevas ideas sobre esta, sino, más bien, como una posibilidad de importar las ideas desarrolladas en Europa varias décadas atrás. Por el tipo de ideas planteadas y la argumentación, se puede considerar a Espacio en el tiempo como una reinterpretación local del libro de Le Corbusier Hacia una arquitectura, publicado en 1923 (Martuccelli, 2000, p. 129).

Aún con la tarea de introducir las ideas modernas de Le Corbusier, Luis Miró Quesada no deja de tener referencias a las características locales, manteniendo un cauteloso nivel de interés hacia nuestra cultura y lo que tenemos de tradición arquitectónica, mientras que no contradiga su interés con la modernidad, o más bien, evidenciando la transición natural, el largo proceso de reforma en la sociedad, que sufrió la región en sus proyectos modernizadores. Dicha transición cultural puede entenderse desde la teoría del "regionalismo crítico" planteado por Kenneth Frampton, como una manera de importar y reinterpretar la arquitectura moderna, presente en el pensamiento de Miró Quesada, aunque sea más probable la tendencia de una "visión moderna con matices locales", que plantea Elio Martuccelli (2000) como una actitud crítica hacia la modernidad, pero no estrictamente confrontacional. La contradicción de Miró Quesada es que la base de la modernidad se encuentra en la desvinculación cultural y territorial del hombre y de la sociedad a la que pertenece. Esta se produce a través de la incorporación del "discurso de las libertades", por lo tanto una actitud verdaderamente moderna apuesta por olvidar el pasado y proyectarse hacia el futuro.

Este discurso encuentra dos limitaciones: la desvinculación cultural y la desvinculación territorial. El hombre, para que sea sujeto de derecho, debe ser entendido abstractamente, es decir despojado de su pertenencia 
cultural. Se hace, por tanto, tabla rasa de la rica diversidad cultural que caracteriza al Perú. (López Soria, 2007, p. 33)

La abstracción en el arte, para Miró Quesada, busca sobrevalorar la participación del artista como creador, con la capacidad de producir la acción creadora, encontrándose por encima de la obra de arte. Refuerza el sentir de la época, que ubica al hombre en el centro de la vida moderna, empujándolo a tomar conciencia sobre su producción cultural. El objeto artístico pierde relevancia, deviniendo en composiciones de elementos y supeditándose al proceso de creación del artista.

[...] Todos los frutos artísticos propiamente contemporáneos $[\ldots]$ sintetizan un proceso de creación artística más personal y espiritualmente elaborado por el sujeto creador. Son expresiones artísticas, como armonizadas composiciones de imágenes humanamente creadas [...] y no ya como mera reproducción de cosas percibidas. (Miró Quesada, 2014, p. 129)

Esta visión subjetiva del arte se plantea no solamente desde la producción o ejecución de la obra misma, sino también con respecto a su interpretación. El arte abstracto libera de toda carga semántica al objeto artístico, buscando la composición pura. Los artistas y arquitectos modernos veían en este nuevo arte la posibilidad de explorar las composiciones por las composiciones mismas, en un acto de libertad total. Una seudolibertad, para ser más específicos, debido a que la libertad total en la creación artística es una posibilidad quizás inalcanzable, pues incluso los impulsos autómatas pasan por un proceso cognoscitivo, aunque evidentemente más aleatorio.

Pero esta libertad en la producción arquitectónica plantea algunos vacíos que los arquitectos modernos no lograron resolver. $\mathrm{La}$ arquitectura como objeto artístico y su finalidad, por la realización del mismo objeto en sí, es algo contradictorio y peligroso. ¿Qué sucede con la función y la solución de los problemas específicos del usuario? La arquitectura no puede desligarse de su carga funcional, se encuentra en su razón de ser. La abstracción como una manera de producir arquitectura, tiene como objetivo y límite la composición formal volumétrica, pero no debe descuidar el terreno de lo útil, diferencia entre la arquitectura y las demás artes visuales.

Los arquitectos modernos en el Perú se plantearon como único problema arquitectónico, la desvinculación con toda tradición heredada de la Colonia, a través de una nueva manera de ver la arquitectura y la ciudad. Buscaban "plasmar composiciones plásticas plenas de aliento formal, mediante el abstraccionismo puro, categórico y cartesiano de la geometría” (Miró Quesada, 2014, p. 133). Era una manera de arrebatarle a la sociedad peruana esa carga cultural ajena impuesta por la Colonia, por otra no menos extraña, pero que responde al tiempo y no a cuestiones políticas.

\section{LA SINTETIZACIÓN DE LAS FORMAS BÁSICAS: "FORMAS" Y "FÓRMULAS"}

Dentro de la propuesta abstracta que se desarrolló en las vanguardias del siglo XX, es fácil entender que la producción arquitectónica moderna tuviera más inclinación por las abstracciones que plantean una sintetización formal, basadas en geometrías puras, debido a que el edificio es en sí mismo una composición volumétrica. Esto significó que la arquitectura moderna atribuyera a este tipo de 
composiciones un nuevo valor estético y una forma de buscar legítimamente la belleza.

A pesar de su gran diversidad, las creaciones de las vanguardias artísticas y arquitectónicas destacan por unos principios formales básicos: falta de jerarquía y de centro, abstracción y carácter antirreferencial, reacción contra la tradición, utilización de mallas geométricas, mecanismos compositivos basados en el collage, búsqueda de formas dinámicas y transparentes, inspiración libre en el universo de la máquina. Todo ello parte siempre de una suspensión del peso de los condicionantes de la realidad (Montaner, 1999, p. 146).

En la arquitectura moderna, la diferenciación entre los volúmenes y la decoración es fundamental. Los arquitectos modernos veían en esta diferenciación una manera de desprenderse de una máscara producida por la historia, una oportunidad para "limpiar" la arquitectura. En el Perú, fue Luis Miró Quesada quien reafirmó esta diferenciación al introducir los conceptos de "formas" y "fórmulas". Para él, las formas se refieren a lo esencial en toda obra arquitectónica; la estructura y la composición volumétrica en general. Por el contrario, las fórmulas se refieren a todo lo superfluo, "un ropaje extraño y falso que recubre y esconde todo concepto verídicamente arquitectónico" (Miró Quesada, 2014, p. 208). De esta manera, las fórmulas se refieren a todo lo decorativo y responden a los estilos arquitectónicos.

El fundamentalismo de la época moderna hace pensar a sus arquitectos que esta diferenciación entre las formas puras y los estilos arquitectónicos es necesaria, y que la arquitectura trabajada a través de formas puras representa la manera correcta de entenderla y producirla. Algunos, a través de este fundamentalismo, llegaron incluso, como en el caso de Miró Quesada, a alentar la formación de nuevos arquitectos con base en esta perspectiva:

Enseñemos por ello a los jóvenes que sienten la vocación de la arquitectura, a buscar directamente la belleza de las puras formas, de manera que cuando plantados - mirada penetrante, corazón alerta- delante de los más perfectos monumentos arquitectónicos de la humanidad, no desperdicien su sensibilidad en un simplista y ramplón estudio de las fórmulas decorativas -trazo de una espiral, elementos de una cornisa, diseño de una ventana, etc.-, sino que capten en la proporción de sus partes, en el balance armónico de sus masas y en la eurítmica unidad de sus líneas generales, la emoción artística de las formas puras. (Miró Quesada, 2014, p. 208)

En esta búsqueda de la sintetización de las formas básicas, la reflexión de Miró Quesada incluye el reconocer la estructura no solo como un elemento que permite la construcción de lo edificado, sino también como un refuerzo compositivo, en la medida en que lo reconocemos como ornamento. Esta actitud típica de la modernidad aparece también en arquitectos occidentales, como es el caso de Mies van der Rohe, quien valora la capacidad expresiva de la estructura.

Los rascacielos manifiestan su enérgica estructura durante su construcción; sólo entonces el gigantesco tronco de acero es expresivo. Cuando se levanta la tabiquería, el sistema estructural que es la base de la composición, se esconde tras un caos de formas insignificantes y triviales. (Benevolo, 2010, pp. 471-472)

Para trasladar esta idea al contexto peruano, Miró Quesada argumenta que existe una 
diferencia entre "ornamento" y "decoración". $\mathrm{El}$ ornamento respeta la estructura y las formas plásticas, realzando la composición. Es racional y aparece como una consecuencia de los procedimientos constructivos. Por el contrario, la decoración es todo elemento que responde a procesos subjetivos que lo determinan como bello. Está relacionado con los estilos arquitectónicos y constituye elementos falsos que se diferencian del edificio. El ornamento se vuelve decoración cuando se saca de contexto, implementándose a manera de fórmula en nuevos contextos sociales. Una solución constructiva es decoración si no corresponde al contexto en el que se aplica, si no es parte de la cultura en la que se inserta.

En este sentido, podemos preguntarnos: ¿qué sucede en el contexto peruano?, ¿no es acaso la arquitectura moderna, con sus soluciones estructurales, un conjunto de elementos decorativos al presentarse fuera de contexto, como lo fue también la arquitectura colonial? Aunque Miró Quesada no identifica ese "vacío", podemos interpretar de su discurso que esta "descontextualización" no se refiere solo al aspecto fisico-geográfico, sino también al temporal. Es la ornamentación de una arquitectura de nuestro tiempo, como un elemento racional-constructivo de evolucionada y lograda cristalización que coadyuva a transformar en dominador un carácter notable de la expresión arquitectónica (Miró Quesada, 2014, p. 217).

La interpretación de una descontextualización temporal es más consecuente con su condición de moderna, que busca la constante negación del pasado. Construye este discurso para reforzar la idea del desarrollo estructural a favor de una sintetización de las formas puras, enfatizando la expresión formal y material de la arquitectura, otorgándole a su desarrollo pleno la connotación de verdaderas. Para Miró Quesada, sobrevalorar la ornamentación tiene como finalidad permitir el desarrollo de la desnudez y la simplicidad como ideas en la nueva arquitectura, "porque, y ello es bueno tenerlo presente, una de las mejores virtudes de belleza de la arquitectura contemporánea radica en su simplicidad" (Miró Quesada, 2014, p. 218).

Con todo lo expuesto, Miró Quesada no estaba en total oposición al empleo de elementos que puedan confundirse como decorativos, siempre que no estuvieran trabajados como fórmulas predefinidas. Identificó que la diferencia entre estructura y revestimiento se encuentra en la inevitable exigencia de la carga material a la que se somete la primera, "liberando" de toda responsabilidad sobre la rigidez del edificio al revestimiento.

Los materiales constructivos, libres de toda función estructural, son entonces empleados específicamente en una función estética de belleza ornamental, constituyendo por sí y sin necesidad de complicados y caprichosos diseños, la auténtica ornamentación de la simplicidad formal de nuestros edificios. (Miró Quesada, 2014, p. 220)

La diferencia entre las fórmulas decorativas y el revestimiento en la arquitectura moderna radica, en primer lugar, en la descontextualización de los elementos, pero también en el desarrollo de la solución material de dicho revestimiento, que enfatiza el desarrollo tecnológico y refuerza la simplicidad de las formas arquitectónicas.

Queda claro que en la reflexión de Miró Quesada es necesario lograr un distanciamiento de la herencia colonial, de una cultura de la decoración excesiva, predefinida y que no 
representaba las inquietudes de la época moderna. Dichas características decorativas impiden una lectura clara de la arquitectura y banalizan la composición volumétrica en un simple uso de fórmulas que se consideran bellas, por encima del desarrollo tecnológico como un nuevo paradigma en la estética moderna. En este sentido, la ornamentación arquitectónica en el Perú del siglo XX, sigue una fundamental característica de simplicidad, una identificación con el espíritu de la obra, y un respeto y exaltación de las superficies y formas arquitectónicas.

\section{CONCLUSIONES}

La introducción de las vanguardias en el Perú se realizó generalmente en los niveles de la cultura dominante, para luego transmitirse a la sociedad total. Como afirma Roger Taylor (1980), el arte es ajeno a las masas, la cultura se transmite en una relación vertical. Esto significó que los preceptos de la arquitectura moderna no tomaran como base la carga cultural de la sociedad peruana para reinterpretarse, sino que se traslaparon, coexistiendo de manera independiente.

Esta coexistencia entre la cultura moderna y la cultura local está presente también en la relación dialéctica entre los conceptos de abstracción y figuración. Dicha oposición no solamente contrapone la representación de la realidad, sino también la posibilidad de otorgar múltiples significados al objeto artístico. Esto implica que en la obra abstracta es necesaria la intervención del espectador, quien completa la obra en un proceso de interpretación.

La abstracción como proceso de diseño arquitectónico plantea la libertad creadora del artista por sobre la obra misma, sin medir que esta sobrevaloración de la composición volumétrica aparta la función de las preocupaciones de la arquitectura. En el campo de lo formal, Luis Miró Quesada interpreta esta exploración compositiva, diferenciando los conceptos de "formas" y "fórmulas". Esta clasificación apunta a identificar qué es lo esencial dentro de la arquitectura, en oposición a lo que es decorativo y responde a estilos arquitectónicos. En esta reflexión, Miró Quesada afirma la importancia de la solución técnico-estructural del revestimiento dentro de la arquitectura, siendo esta la gran diferencia con las fórmulas decorativas preexistentes.

En toda la revisión de lo abstracto en el pensamiento de Luis Miró Quesada, podemos evidenciar una convicción sobre la cultura moderna y su intención de introducirla al contexto peruano, reinterpretándola en la producción arquitectural, encontrando sus lógicas. Dicho proceso ha sido inevitable, pero con la distancia que ha permitido el tiempo solo queda preguntarnos: ¿qué nos ha dejado la arquitectura moderna en la búsqueda legítima por una identidad arquitectónica peruana?, ¿no es acaso la introducción de la modernidad una imposición del siglo XX, que no es mejor o peor que la ejecutada por la Colonia, sino solamente diferente?

\section{REFERENCIAS}

Benevolo, L. (2010). Historia de la arquitectura moderna (8. ${ }^{a}$ ed.). Barcelona: Gustavo Gili.

Castrillón, A. (2002). De abstracciones, informalismo $y$ otras historias. Lima: ICPNA. Recuperado de http://www.urp. 
edu.pe/urp/modules/institutos/invest_ mus/abstracciones.pdf

López Soria, J.I. (2007). Adiós a Mariátegui. Pensando el Perú en perspectiva postmoderna. Lima: Fondo Editorial del Congreso del Perú.

Martuccelli, E. (2000). Arquitectura para una ciudad fragmentada. Ideas, proyectos $y$ edificios en la Lima del siglo XX. Lima: Universidad Ricardo Palma.

Miró Quesada, L. (15 de mayo, 1947).Expresión de principios de la "Agrupación Espacio". El Comercio. Lima.
Miró Quesada, L. (2014). Espacio en el tiempo. La arquitectura moderna como fenómeno cultural (1. ${ }^{a}$ ed., vol. 4). Lima: Facultad de Arquitectura y Urbanismo. Pontificia Universidad Católica del Perú.

Montaner, J.M. (1999). La modernidad superada. Arquitectura, arte y pensamiento del siglo XX (3. ${ }^{a}$ ed.). Barcelona: Gustavo Gili.

Taylor, R. (1980). El arte, enemigo del pueblo. Barcelona: Editorial Gustavo Gili. 